\title{
The Bored Self in Knowledge Work
}

\author{
Costas, Jana; Kärreman, Dan
}

Document Version

Accepted author manuscript

Published in:

Human Relations

DOI:

10.1177/0018726715579736

Publication date:

2016

\section{License}

Unspecified

Citation for published version (APA):

Costas, J., \& Kärreman, D. (2016). The Bored Self in Knowledge Work. Human Relations, 69(1), 61-83. https://doi.org/10.1177/0018726715579736

Link to publication in CBS Research Portal

\section{General rights}

Copyright and moral rights for the publications made accessible in the public portal are retained by the authors and/or other copyright owners and it is a condition of accessing publications that users recognise and abide by the legal requirements associated with these rights.

Take down policy

If you believe that this document breaches copyright please contact us (research.lib@cbs.dk) providing details, and we will remove access to the work immediately and investigate your claim. 


\section{The Bored Self in Knowledge Work Jana Costas and Dan Kärreman Journal article (Post print version)}

This article was originally published in:

\section{Human Relations}

First published online: 30 September 2015

DOI: $10.1177 / 0018726715579736$

Uploaded to Research@CBS: November 2015

Available at:

http://research.cbs.dk/da/publications/the-bored-self-in-knowledgework\%28fa5c10b5-4a7f-4790-8526-1639eda7b125\%29.html 


\begin{abstract}
This paper draws attention to reported experiences of boredom in knowledge work. Drawing on extensive qualitative data gathered at two management consultancy firms, we analyze these experiences as a particular interaction with identity regulation and work experiences. We conceptualize the reports of the bored self as a combination of unfilled aspirations and the sense of stagnation, leading to an arrested identity. Our contribution is to expand extant conceptualizations of employee interactions with identity regulation, in particular relating to identity work and identification. The findings provide a critical rendering of the glamourized images of knowledge work.
\end{abstract}

Identity regulation has become a central way to study the relation between employees, work and the organization (Alvesson \& Willmott, 2002; Collinson, 2003; Sveningsson \& Alvesson, 2003; Empson, 2004; Kärreman \& Alvesson, 2004; Thomas \& Davies, 2005; Cornelissen, 2006; Alvesson \& Kärreman, 2007; Alvesson et al, 2008; Watson, 2008; Nicholson \& Carroll, 2013; Carroll \& Nicholson, 2014). By reinforcing certain values, norms and believes, identity regulation is seen to indirectly target the very construction of employees' sense of self. It has remained contested how employees respond such attempts. Research has drawn attention to a variety of interactions, such as identification, ambivalence, dis-identification and self-alienation (Kunda, 1992; Pratt, 2000; Collinson, 2003; Alvesson et al., 2008; Costas \& Fleming, 2009). In this paper we explore what we believe constitutes a different kind of interaction, namely that of the bored self. Rather than embracing or distancing oneself from the exhorted organizational self, boredom indicates a kind of arrested identity founded on unfulfilled expectations and the sense of stagnation.

Of course, boredom has been reported as one typical experience of modern life (Healy, 1984; Goodstein, 2006). One just has to think of the iconic images of Charlie Chaplin's Modern Times and Felix Lang's Metropolis: the repetition and monotony of work practices in 
industrial and bureaucratic set-ups leave little room for creativity and self-expression in the labour process. This leads to a flattened out sense of dissatisfaction, disengagement and simply ennui, which workers may attempt to overcome through 'making out' and engaging in various games (Roy, 1959; Willis, 1977; Burawoy, 1979). What is puzzling about the experience of boredom we explore in this paper is that they are reported in a context that is supposedly radically different from the industrial and bureaucratic set-up, namely that of knowledge work. Such work is commonly understood as giving individuals space for creativity, problem-solving and therefore self-fulfillment (Starbuck, 1992; Blackler, 1995; Newell et al., 2009). Tasks are regarded as complex and varied so that work practices cannot follow prescribed routines. This in turn implies that knowledge work arrangements mostly employ highly qualified individuals who are granted considerable levels of autonomy and independence in their daily work life.

Given this, why do knowledge workers report boredom? We empirically explore this question by drawing upon extensive qualitative data gathered at two globally operating management consultancy firms that are generally regarded as creative, intellectually demanding and prestigious workplaces. We suggest that one way to understand these experiences is by relating them to the workings of identity regulation, which is a pervasive form of organizational control in knowledge work arrangements.

In doing so, the paper seeks to make two contributions. We add to the understanding of employee interactions to identity regulation by drawing attention to how individuals can continue to aspire to the identity suggested by management discourses although this identity cannot be enacted in daily work reality. This leads to an identity arrest which drains individuals from drives to mobilize alternative selves. Furthermore, we contribute a more nuanced understanding of everyday work experiences of knowledge work. By drawing attention to knowledge workers' reports of boredom, our paper questions the conventional wisdom regarding the nature of knowledge work. 
The structure of the paper is as follows: First, we discuss studies of identity regulation and the ways in which employees are typically seen to interact with it. Second, prevailing renderings of knowledge work are outlined. Third, after methodological considerations, the management consultancy firms empirically investigated are introduced. Fourth, we analyze the reported sense of boredom by relating it to identity regulation and work experiences. Fifth, the discussion develops the significance of the bored self in knowledge work in relation to conceptions of identity work and identification. This is followed by concluding reflections on the glamourized image of knowledge work.

\section{Identity Regulation and Employee Interactions}

Identity regulation is one common way in which management seeks to indirectly shape and influence employee selves (Alvesson \& Wilmott, 2002; Thomas \& Davies, 2005; Cornelissen, 2006; Watson, 2008; Costas \& Kärreman, 2013; Nicholson \& Carroll, 2013). Cultural resources and practices, such as team exercises, company slogans and value statements, are typically seen as ways in which management attempts to manage meaning and instill values and emotions. In this way, particular identities beneficial to the organization are exhorted (Kondo, 1990; Van Maanen, 1991; Kunda, 1992; Casey, 1995; Parker, 2000). More specifically, identity regulation constitutes the construction, production and maintenance of symbols infused with a particular meaning and preferred interpretation, which aim to prompt individuals to engage in particular forms of identity work (Alvesson \& Willmott 2002). Such attempts to regulate individuals constitute a form of normative control (Kunda, 1992; Barley \& Kunda, 1992). This differs from traditional forms of bureaucratic and technological control, 
e.g. strict formal protocols, surveillance and monitoring, that directly target outputs and behavior (Alvesson \& Kärreman, 2003; Kärreman \& Alvesson, 2004).

Identity can be viewed as a construction and performance that is constituted through discourses and practices (Gioia et al 2000; Sveningsson \& Alvesson 2003; Collinson 2003; Alvesson et al 2008). Identity work takes place in a social and interactive process of enacting a shared identity within a certain setting, such as a work community (Alvesson \& Willmott, 2002; Watson, 2008). This means that our identities are inherently negotiated and potentially contested (Thomas \& Davies, 2005). Identity work always occurs in interaction with the surrounding discourses and practices. Management can seek to tap into this in various ways. For instance, in order to enact particular employee identity work it may attempt to provide a certain organizational membership role, and the scripts to identify with the role (Kunda, 2006).

Studies have also suggested that management might co-opt identity resources relating to consumer culture (Land \& Taylor, 2010), ethical and responsible orientations (Costas \& Kärreman, 2013), lifestyles (Fleming \& Sturdy, 2009) and broad societal discourses (Ybema et al., 2009) to establish and strengthen ties between employee identity vis-à-vis the organization. In particular this can occur through the exercise of aspirational control (Roberts, 2005; Alvesson and Kärreman, 2007a; Thornborrow and Brown, 2009; Costas \& Kärreman, 2013). Such control provides identity material that is perceived to be attractive for and aspirational to the employee self, such as high status, well compensated and elite understandings of selfhood (Robertson \& Alvesson, 2006).

Attempts to regulate identity can result in different interactions and enactments amongst employees, such as identification, dis-identification, ambivalence, self-alienation and of course exit (Pratt, 2000; Collinson, 2003; Kunda, 2006; Costas \& Fleming, 2009). For instance, identification takes place when employees construct their self around the identity material suggested by the organization (Elsbach, 1999). Thus, the sense of self becomes 
strongly aligned with the organization (e.g. Grey, 1994; Kuhn, 2006). In consultancy firms, research has shown how individuals may strongly identify with the ethically responsible self designed by the companies' CSR initiatives (Costas \& Kärreman, 2013). However, such identification may build upon robust constructions of the company self that become problematic in times of change (Sennett, 1998).

Dis-identification, on the other hand, implies that employees may reject the identity exhorted by management discourse; they distance themselves from this identity as it is experienced as fake, inauthentic and/or morally compromised (Holmer-Nadesan, 1996; Elsbach \& Battacharya, 2001). Among other things, studies have drawn attention to cynical selves, humour and forms of resistance by mobilizing alternative selves (Collinson, 1992; Fleming \& Spicer, 2003; Taylor \& Bain, 2003; Kosmala \& Herrbach, 2006). Whilst such disidentification may provide individuals with a perceived space of autonomy outside of management regulation, this very space may ironically allow them to smooth over the contradictions of management discourse and practice and thus operate more effectively (Fleming \& Spicer, 2003).

Of course, such identification and dis-identification may not occur in a clear-cut fashion. Employees may express ambivalence in that they embrace certain aspects, whilst rejecting other aspects of the identity material provided by management discourse and practice (Pratt, 2000; Kunda, 2006). A further interaction has been discussed as self-alienation whereby individuals seek to, yet cannot dis-identify because of the experienced lack of alternative identity resources (Costas \& Fleming, 2009). Of course employees may also exit the organization and thus move away from the attempts of identity regulation (Pratt, 2000; Kärreman \& Alvesson, 2009; Costas \& Grey, 2013).

\section{Knowledge Work}


Knowledge work is typically framed by attempts towards regulating identity and thus aligning individuals with the organization. This is a consequence of the very nature of knowledge work. Management research commonly contrasts it with bureaucratic and industrial forms of work, which are associated with tedious, repetitive and monotonous labour. Knowledge work differs from this, as here value is created through knowledge rather than labour or capital (Blackler, 1995; Morris \& Empson, 1998; Newell et al., 2009). Knowledge is, undoubtedly, ambiguous (Alvesson, 1993) and important to most organizations (Schreyögg \& Geiger, 2007). What is particular to knowledge work is the centrality of 'esoteric expertise' (Starbuck, 1993), namely of specific, rare and abstruse knowledge, in the work practices (Kärreman, 2010). As the intellectual abilities and specific expertise of the workforce are the main resources, knowledge workers are usually highly qualified and talented individuals. Furthermore, knowledge work is largely understood to be characterized by creativity, problem-solving and task complexity instead of routines and standardized work processes (Lowendahl, 1997; Newell et al., 2009). As Newell et al. (2009) note: "knowledge workers typically expect to be given interesting and varied work rather than follow a prescribed routine" (2009: 127). This requires that they are granted a high degree of self-organization and work in relatively loose team structures outside the direct supervision of management.

However, this does not mean that knowledge work is completely free of organizational control. At the same time as traditional forms of bureaucratic and technological control e.g. strict formal protocols, the regulation and monitoring of output, are arguably more difficult to execute, normative control assume significance in knowledge work (Grey, 1994; AndersonGough et al., 2000; Alvesson, 2004; Kunda, 2006; Poulter \& Land, 2008). In this sense, the target of control is not so much behavior or the measure of output as it is how employees define themselves (Alvesson \& Willmott, 2002). Research has, for instance, shown how knowledge workers' identities are disciplined through performance targets and mentoring processes (Covaleski et al., 1994), time management systems (Anderson-Gough et al. 2001) 
and routines of time-keeping and billing (Brown \& Lewis, 2011). Having said that, Kärreman and Alvesson (2004) also demonstrate that identity regulation as one form of control can occur "in tandem" with bureaucratic controls, exercised through formal HRM procedures, hierarchical structures, division of labour and knowledge management systems. Rather than approaching knowledge work as autonomous and free of control, this strand of research suggests that it is also subject to forms of control, which entail discipline (Bergström et al. 2009, Brown \& Lewis, 2011) and compliance (Kärreman \& Alvesson, 2009).

In this study we seek to add a richer understanding of knowledge work by exploring people's everyday work experiences. In this sense, our study heeds Barley and Kunda's (2001) call that our field has moved too far away from engaging with "what people actually do". This can lead to "anachronistic theorizations and outdated images of work" (2001: 90) and even worse, we add, reproducing the work ideals and images fostered by prevalent discourses on knowledge work that may be far from people's everyday work experiences. Our interest lies in one particular and arguably under-studied reported experience, namely that of boredom in knowledge work.

That work can be boring is perhaps not in itself surprising. Research on labour processes, for example, suggests that the deskilling and high levels of technocratic control resulting from the industrial and bureaucratic set-up renders work monotonous and boring. As shown by the classic studies of Roy (1959), Willis (1977) and Buroway (1979), workers respond to this by engaging in games, counter-cultural activities and 'making out'. Moreover, there has been research focusing on boredom more directly relating to job design in industrial and bureaucratic work. It regards boredom as an objective "property of jobs associated with industrial, not post-industrial knowledge economies" (Loukidou et al., 2009: 388). Whilst these studies have provided important insights on work experiences and particularly boredom, their insights have less explanatory value for the work setting we are concerned with, namely that of knowledge work. Indeed, knowledge work is often framed as overcoming the 
particular drawbacks of industrial and bureaucratic work by providing more degrees of freedom and discretion (Thompson et al, 2002). Thus, the prevalence of reported experiences of boredom is a mystery - one which we seek to resolve in this paper.

We approach this mystery through exploring the emic understandings of boredom. Taking on a social constructivist view, we are concerned with how boredom is ascribed to certain activities and situations, how it is made sense of within particular social contexts and how this in turn shapes identity and meaning. We do not regard boredom as necessarily negative (or positive), but instead are interested in the various ways in which actors in the field understand and relate to it (see also Spacks, 1995; Carroll et al., 2010). Thus, our starting point are the reported experiences of boredom articulated by the informants in the field rather than existing objective (relating to job design) or subjective (relating to personal traits) definitions of boredom as conceptualized by the boredom literature (Kafry \& Pines, 1980; Fisher, 1993; Genmill \& Oakely, 1992; Melamed et al., 1995; Vodanovich, 2003; Loukidou et al., 2009; van der Heijden et al., 2011). In this sense, we follow Carroll et al. (2010) who look at the different ways in which leadership socially constructs boredom and its interaction with discourses of challenge and change. They argue that despite its negative connotations, boredom may in fact "spur" leadership by providing "an opportunity for reflection, a pathway to enlightenment and a chance to create order out of chaos" (2010: 1046). Building on that, we move the focus from leadership to knowledge workers and their particular work context.

\section{Methodology}

The empirical basis of this paper is founded on two studies of large, globally operating management consultancy firms, Global Consulting (GC) and Elite Consulting (EC). These studies were independently conducted by the authors but yielded similar insights concerning work experiences, identity regulation and knowledge work. Methodologically, the field 
studies are based on participant observation, interviews and documentary analysis. The fieldwork of the first study was conducted during five years at Elite Consulting. The empirical material consists of transcripts from 52 interviews with 45 persons, as well as notes from participative observation in several organizational gatherings. The participative observation includes following a team for two work days, participation in training sessions, in various settings where organizational members communicated internally, such as in competence group meetings and the annual meeting for all managers, and externally, such as when presenting the company to students. The second study is based on a total of 57 interviews (from analyst to director level), which on average lasted one hour at both organizations. Being part of an internal HR team the author, moreover, conducted participative observations at EC. At GC she informally engaged with the consultants, by going for lunches, coffees and after work drink. The second study also entails the documentary analysis of HR documents, company websites and recruiting brochures.

It is important to consider the risks for over-relying on interview accounts when making specific claims of how people 'really' think or experience their work (Alvesson \& Kärreman, 2011). Interviews like any social interaction can only be managed to some degree and such efforts can create unforeseen side-effects. There are complexities far beyond what may be seen as 'errors'. This means that interview statements must be understood in their local, situation-specific context. In interviews people are not reporting external events but producing situated accounts, drawing upon existing cultural resources. However, this is less of a problem in our study, since we are not aiming for objective truths but rather for the cultural resources at hand when describing work experiences. Our interview material is also supplanted with observations of everyday conversations between consultants - material that is not restricted by the shortcomings of the interview situation. Moreover, in this particular study, we have the unusual advantage of drawing on material generated in different contexts and countries, and interviews conducted by different researcher of different gender and levels 
of seniority. Indeed the prevalence of boredom in both data sets is especially surprising since it was not generated by the original research questions and thus prompted by leading questions. Both studies used exploratory questions to address the overarching research themes of organizational culture and identity (study 2) and of the characteristics of knowledge work (study 1).

Given the similarities of the companies, we did not conduct a comparative analysis but rather analyzed the empirical material around themes. Our data analysis process followed the logic of abduction (see Van Maanen et al., 2007; Alvesson \& Kärreman, 2007b; Locke et al., 2008); the empirical field was approached through established conceptions concerning knowledge work (autonomy, creativity, expertise), culture (meaning, symbols, values) and identity (socialization, identification, roles), yet these were modified in the course of the study given the emergence of the theme of boredom.

Thus, the data analysis process was characterized by openness and the search for surprising phenomena, in our case boredom, which do not fit and even contradict the extant literature's general framing of knowledge work as creative and autonomous. This made us rethink our assumptions and conceptualizations - something that entailed a creative theory building process concerning boredom in knowledge work. This is not to say that every consultant reported boredom (indeed, it is much more in line with the image of and management discourse around knowledge work to emphasize the creative and glamorous aspects of such work and thus of oneself as a knowledge worker). Put differently, the selfreported cases we are concerned with are particularly significant insofar as they contradict the aspirational conceptualization of knowledge work and the knowledge worker. It should also be stressed again that in analyzing these reports, we focus on the emic understanding of boredom, i.e. our interest is not in applying a particular conceptualization of boredom but rather in the meanings expressed by the informants. In coding our data on boredom we developed how the reported experiences of boredom relate to identity work and regulation in 
a knowledge work setting. Thus, we use the notion of boredom as a first-order concept (one that is used by the informants in their everyday language) and we analyze this through the second-order (i.e. theoretically driven) concept of identity regulation (see Van Maanen, 1979). From our data we developed coding pairs, such as creativity versus repetition or career/development versus stagnation, around which we structured the locus of reported boredom:

1. Creativity $\leftrightarrow$ Repetition

2. Autonomy↔ Standardization

3. Learning $\leftrightarrow$ De-skilling

4. Expertise $\leftrightarrow$ Clerk Work

5. Elite $\leftrightarrow$ Nobody

This data structure constitutes the basis for our empirical analysis and discussion of experiences of boredom and identity regulation in knowledge work.

\section{Introduction to the Cases}

The firms empirically investigated are multi-services professional organizations. This paper focuses on the consulting branch. They can be classified as knowledge-intensive firms: a large proportion of resources are spent on personnel; the companies recruit qualified individuals with academic degrees; and the client services are non-standardized, idiosyncratic and require individual judgment. Both our cases specialize in management consultancy but with an emphasis on the development and implementation of administrative and technical solutions to organizational problems. The projects are often relatively large, involve several or even dozens of people, and may last for several months or even years. People are known to work 
hard and frequently experience very long working days - many say that they often work 6070 hours per week.

Formal structure varies with perceived problems and fashion, but the key unit is the project team. Projects are carefully contracted, designed and monitored. Project teams are temporary and the composition of people working together varies over time, partly due to the variation of assignments, and partly due to the fact that the development of employees means they get more senior project roles over time.

Despite the adhocratic nature of work, the organizational hierarchy is strongly pronounced and formalized, with several career steps and associated titles. Most people see the hierarchy as functional, enabling productive division of labour. Standards, rules and procedures are strongly pronounced. There are rules for dealing with most issues, e.g. elaborated lists of criteria for appraisals and rules for dress codes, which are applied with discretion. There are frequent appraisals and rankings of organizational members, which determine their career development and salary (which are high within the industry). Formal appraisals take place several times per year for younger employees, less frequently for senior employees. A lot of attention is given to rankings and promotions. Low rankings and promotions below medium time frames are clear signals that people must improve or ought to consider leaving the firm. Turnover rates are high in both companies, particularly amongst analyst and consultant levels (e.g. about one third of analysts leave the companies within the first two years) - something that we will return to later on when discussing the functions and dysfunctions of the experiences of boredom.

There is a strong cultural emphasis on performance and delivery. Social relations are generally developed and maintained in projects and teams where they can be both intimate and intense, although limited in time. Recruitment and selection are standardized and formalized. Almost all organizational members come directly from top universities and have various academic backgrounds, such as business administration, engineering, history and 
French. Recruitment interviews emphasize the high demands on employees: on being flexible, able to travel a lot and, at times, to work long hours. They tend to rank high in employer rankings and thus are considered to be attractive workplaces.

\section{Boredom at Global Consulting and Elite Consulting}

Consider these extracts from our interview transcripts:

I find the work quite frustrating and boring and I mean I can be very open and say that I don't love the work I do here... It is very difficult for me the more I work here to find something interesting, something I enjoy within the company (consultant, EC)

It is bad when you are working like you are on an autopilot... Sitting in front of your computer and doing the same thing all over again (analyst, GC)

The actual nature of work it is very dry material and you actually have to approach it in a clinical, professional mindset, you can't be necessarily creative and artistic and philosophical about it. ... It is not necessarily an intellectual place... Someone referred to it once as the McDonald's of the consultancy world. I mean it is very true" (consultant, EC)

These sentiments were surprising to us, but not in the sense that the occasional consultant may feel fed up and bored with his or her work. The surprise is rather the wide-spread nature, as we will demonstrate below, of the sentiments. Boredom does indeed seem to be an integral experience of work in these companies. We suggest that such reports of boredom in this context arise as a result of clashes between the company discourses concerning the nature of 
work and thus of the consultant identity and the consultants' everyday work experience. In this respect, boredom is reported in relation to five clashes, which we have termed: creativity $\leftrightarrow$ repetition, autonomy $\leftrightarrow$ standardization, learning $\leftrightarrow$ de-skilling, expertise $\leftrightarrow$ clerk work, elite identity $\leftrightarrow$ 'nobody'.

\section{From Creativity to Repetition}

The official company discourses apparent in the firms' website, brochures and recruitment leaflets emphasize the creative nature of consulting work and the creative consultant. For instance, the companies advertise that they sell "creative solutions" (GC) to clients, as they "apply innovative thinking that anticipates emerging trends and influences" (EC). They depict themselves as being "one step ahead" (Elite Consulting) of the market, given the "groundbreaking research and thought-provoking insights" (GC) their "dynamic, innovative and forward-thinking" (HR manager, EC) workforce produces. Moreover, consulting work is depicted as interesting and thought-provoking, involving varied and multifaceted tasks: "there is not a typical day... things vary, everyday Elite Consulting is different" (consulting in recruitment video). As a result, individuals, and specifically graduates entering these companies, expect to be conducting inspiring and creative work and thus being inspired and creative themselves.

However, consultants report how these expectations clash with their everyday work experience. Rather than finding the work interesting, intellectually challenging and creative the impression provided by company discourses - it is seen to be tedious, repetitive and, indeed, boring. Whilst company discourses raise expectations concerning creativity and innovation, consultants, particularly those at the lower hierarchy levels, feel that these expectations remain unfulfilled in their everyday work life - something that brings about experiences of boredom. 


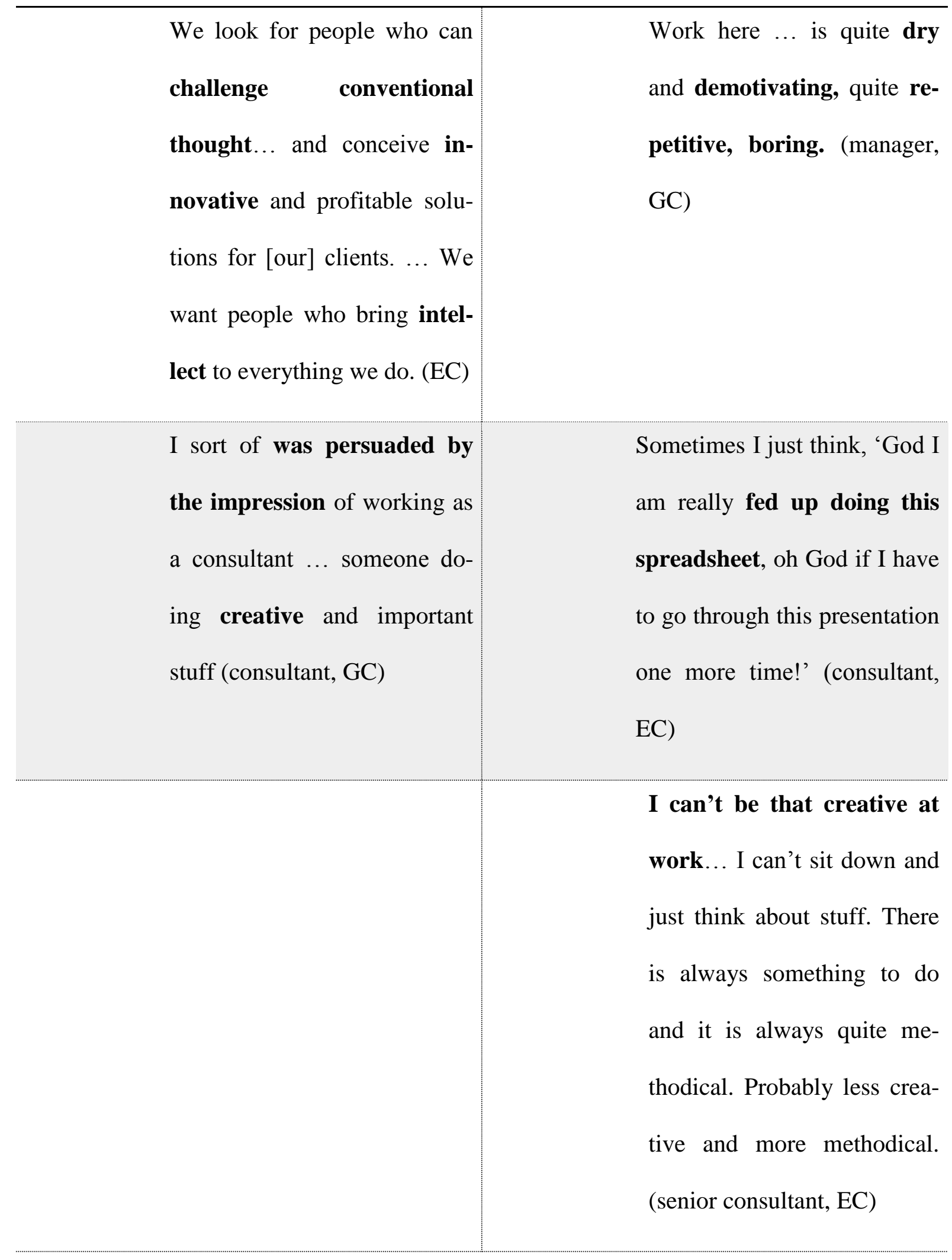

Table 1. Creativity vs. Repetition discourse 


\section{From Autonomy to Standardization}

Related to this, the companies' discourses depict the work as providing individuals with lots of autonomy and responsibility. For instance, consultants remarked frequently how recruitment campaigns fostered their expectations that the consultant role gives them lots of choice and project responsibility. Not only do consultants approach their work with the expectation of having choice with respect to the project they work on and the everyday work practices they engage in (e.g. how they respond to client demands), but also in terms of being able to independently interact with clients. Being a consultant is depicted to entail lots of "responsibility from day one" (GC), as individuals help high-level business leaders to tackle complex challenges. A manager (EC) summarizes how in the recruitment events the image is fostered that consulting work is "cutting edge, challenging and interesting", as employees “interact closely with senior clients" and "work on different projects in different places". As a result, consultants' expectations concerning their everyday work and their work self were constructed around not only being creative but also autonomous and independent.

However, these expectations clash with their everyday work experience. Consultants report engaging in repetitive activities that grant them little space for making autonomous decisions and for thinking and interacting independently with clients. Given that the companies also engage in bigger projects that largely focus on implementing certain software systems or strategies, their work can follow certain defined methodologies and standards. There is a strong emphasis on delivery and "getting things done" (manager, EC):

\section{Autonomy discourse}

\section{Standardization discourse}


So, when they did this GC [recruitment] presentation, they talked about the group ... that was like exactly what I wanted to do, they provide you with a lot of choice. (analyst, GC)
There is not much space for just

thinking or reflecting very much even if you're looking at the work and your responsibilities in front of you. It is just very much a do it and do the next thing and do the next thing. (manager, GC)

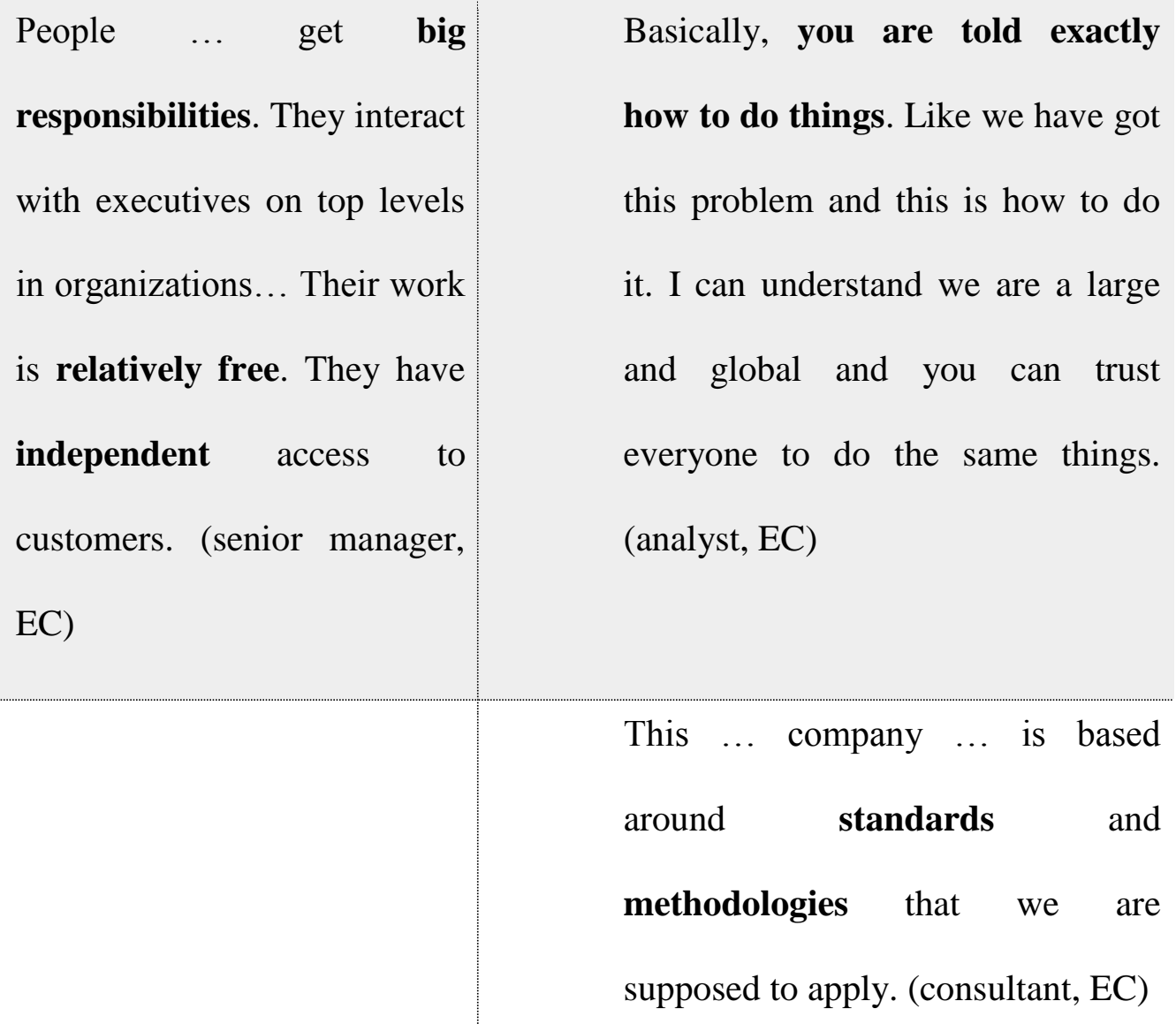

Table 2 Autonomy vs. Standardization discourse 


\section{From Expertise to Clerk Work}

The clashes of expectations in relation to experiences of everyday work and the consultant self are further reinforced through the lack of expertise consultant feel that their work requires. Whilst company discourses stress that the consultant is an expert with specialized knowledge, individuals report the opposite. Consultants at the lower ranks of the hierarchy seem especially prone to report boredom as here the clash between expectations concerning the nature of work - and of the suggested consultant identity - and their everyday work experience is pronounced. Individuals state having to engage in routine work that remind them of clerk work that requires little knowledge or expertise. As one manager explains, when he started working at EC he got very "bored ... having to do monotonous work... [so that] you ask yourself for what have I done my university degree”. Indeed, consultants state that they have to do "something very dull like writing interview notes up or proof-reading something" (senior consultant, GC) or "checking commas in the appendix of the presentation" (analyst, EC).

One might argue that doing rather uninspiring work that requires little expertise and provides little autonomy is part of starting in a job and that this changes as one moves up the hierarchy. Yet consultants experiencing boredom do not seem to believe in this trade-off, i.e. engaging in monotonous work in the present for autonomy and creativity in the future. This

might be the case not only because they feel that company discourses already raised unfulfilled expectations concerning their situation in the present, but also because they feel that the cultural emphasis on learning and development is in tension with their everyday work experience, which is considered to involve some kind of de-skilling instead. Thus, rather than development and progress, they express themselves as stagnating, or even worse, regressing something that can further explain the reported experiences of boredom. 
During its projects EC calls in expert knowledge. (EC)
Serving an analyst role ... often

[involves] large workloads, often

quite monotonous work...

There is a lot of bad and uninspiring work to do for analysts. (manager, GC)

Probably when you are at junior grade there is sometimes little effort to give you interesting things to do. You just meant to be the kind of, in some projects, the useful enthusiast who regardless what work is just says 'yeah, give me more, I love it, I love doing this, filing out some numbers is great.' (consultant, EC) 


Our "high performance business"
strategy builds on our expertise in
consultancy $\ldots$ to help clients
our industry knowledge, service-
capabilities,

Table 3 Expert vs. Clerk work discourse 
At GC and EC the official discourses celebrate the great chances for learning and development consulting work offers. Indeed, for this reason they present themselves and are often depicted in relevant newspapers and magazines as "top employers", especially for graduates. GC and EC employees are seen to benefit from incomparable opportunities. These opportunities of learning and "growing" (EC) are viewed to result from the fact that consultants work with a diverse and highly talented group of people, are offered formal "tailor-made and wide-ranging programmes of ... education and training" (GC), and have access to diverse, international and exciting projects of high impact. The firms' large and superior client base across the world is said to offer exceptional "real-time learning opportunities" (GC). For instance, graduates are said to be provided with relevant "training and development opportunities to launch [their] career on the right track" (GC) and experienced hires are given the "opportunity to stretch [themselves], speed up [their] career progression and apply [their] expertise to bigger and more complex projects" (EC).

Yet consultants report that these expectations raised by company discourses are not fulfilled and clash with their everyday work experience. Indeed, individuals report boredom given that the kind of work they engage in leads to de-skilling. Moreover, boredom is associated with staying on a certain project for a long or seemingly never-ending time something that contradicts the image of the knowledge worker as having lots of learning opportunities and varied experiences.

This suggests that instead of learning and developing, individuals experience themselves as stagnating in their development or even worse regressing, i.e. losing their abilities. This sense of not developing, we propose, can further explain the prevalence of reported boredom amongst consultants. It shows in particular how the experiences of boredom in everyday work life relate to the consultant identity fostered by management discourse, which will be developed below. 
Learning discourse

Whatever your experience, we'll help you to expand your knowledge and

skills - whether this is through our formal training programs, by tapping into our international network of consultants, or through exposure to some of the biggest challenges in global commerce. (EC)

\section{De-skilling discourse}

We were just talking about our work we were doing at the moment and we were saying that it is probably causing us some amount of brain damage, that we probably lost some mental capacity that will never get back. We call it 'irreparable damage' by doing this work. (consultant, EC)

Ready for a career like no other? When does the learning stop at Global Consulting? Simple. Never. ... We regard unfulfilled potential as waste bordering on tragedy - it's anathema to our culture. (GC)

Our "high performance business" strategy builds on our expertise in consultancy $\ldots$ to help clients perform at the highest levels. Using our industry knowledge, serviceoffering expertise and technology capabilities, we identify new business and technology trends. (GC)
I am still relying on the knowledge when I came to the firm... I don't think that you get the exposure [in relation to client projects] ... I don't think that I get the right opportunities here. (analyst, GC) They are not investing enough in us individuals to skill us up for the future, it really little training and learning opportunities. (manager, GC) just doesn't seem to happen. There is 
One of the main things $\mathrm{I}$ joined the company for was the variety of experience, lots of different clients, big names, and the training and just learning a lot. I kind of feel that I don't get that training, I am not learning that much anymore. (consultant, EC)

I hear people working hours and hours every day, getting stuck on projects for years, without any chance of change... (analyst, GC)

A lot of people that were leaving were people that had done similar roles to me, which I had not enjoyed, around process design, which I think is fine to do it once, but assuming you don't want to do this again. I thought the firm was guilty of making these people do that same role again and again. (consultant, EC) 
One of the problems we have is that we say to people that there is lots of variety, lots of career opportunity. But the reality is that you are looking for a project, you are matching together a small number of people that are available to a small number of projects. At that point the business will not look at whether the individual finds the project interesting or not. (director, GC)

Table 4 Learning vs. De-skilling discourse

From Elite Identity to 'Nobody'

At GC and EC company discourses reinforce constructions of consultants as elite knowledge workers. Such an elite identity is created on the basis of the image these companies enjoy in the industry, on the of basis that their clients are large and influential corporations, that they are highly selective in their recruitment, and that most consultants have degrees from top universities. Individuals are encouraged to make sense of themselves in the ideational ways in which the firms portray consulting work and thus the consulting identity. The companies' discourses foster a consultant elite identity that draws on glamour, high status, excitement and creativity. However, this suggested ideational identity construction clashes with the consultants' reports of everyday work as boring. Rather than living out some kind of elite 
identity they come to feel like a "nobody" - a person doing the "least bourgeois" (manager cited above) work:

\section{Elite discourse 'Nobody' discourse}

I sort of was persuaded by the impression of working as a consultant $\ldots$ someone doing creative and important stuff (consultant, Global Consulting).
When people join they think that

Global Consulting, the culture, the employees, is going to be some glamorous creative job in strategy et cetera, et cetera. ... We get those people from Oxford and Cambridge, Edinburgh, the top basically. But then they find themselves doing very technical stuff for the first couple of years... it is the least bourgeois work. They hate it... (manager, GC). 
There was a lot of hype around Global

Consulting and it seemed so glamorous and exciting (analyst, Global Consulting).
People have a perception of consultancy that does not meet reality. The work can be far more mundane than they imagine. My knowledge about it was very different to the reality... You don't really think about that it would be so mundane when you see Global Consulting being advertised. It looks far more glamorous and you think, 'wow, that looks good'. (consultant, GC) 
It is the image of those kind of companies [that made them think that] they were very impressive (senior consultant, Elite Consulting).

Table 5 Elite vs. 'Nobody' discourse
When I joined, I thought I would

be a glamorous, high-flying business woman. I just really thought that it would be really glamorous, carrying a Prada briefcase and Prada heels. I did not expect such sort of work [i.e. tedious testing] at all... With the kind of work I was doing I was absolutely devastated, I am still quite devastated... When you apply to this company as much as to most graduate jobs your perception to what you will be doing is different to what you will actually be doing. (consultant, EC)

\section{Discussion}

Our analysis has shown how boredom is reported in knowledge work. Consultants express this in different wordings, such as referring to themselves as frustrated and devastated and the 
work as being dry, dull, monotonous and repetitive. Whilst, say, devastation does not necessarily imply boredom, in the context of our cases the quotes above generally relate to different expressions of ennui (e.g. the quote of devastation presented above on the 'nobody' discourse was uttered in the context of describing feelings of being stuck with repetitive testing work). Indeed, boredom, being bored, doing boring things are the most frequent expressions of negative work experience used by the consultants. Again we do not claim to judge whether they are objectively bored. Instead we want to explore and question why this particular term is evoked by the consultants. What is its meaning and what does it tell us about the work context?

In some ways, the data suggest that boredom simply results from the nature of work, which some even associate with industrial and bureaucratic set ups. However, this does not mean that consulting work is in fact comparable to McDonald's, a metaphor used by one consultant cited above. There are still important differences. As aforementioned, consultants are granted more discretion in their daily work life, they work with other highly qualified employees and given the high prestige of these companies, they have much greater career prospects in terms of salary and development. That is, consultants can easily find senior jobs in the industry (see Sturdy \& Wright, 2008). Whilst the work may also entail routine aspects and thus be at times unexciting, it is not fed to them in precise pieces supposed to be assembled according to set procedures at a pace decided by a conveyor track. Thus, a labour process argument cannot fully explain the reported experiences of boredom.

It is also perhaps tempting to discount some, if not all, of the reports as the 'whining' of the privileged. That management consultancy work is tedious and taxing toil is hardly news, and elite students from elite institutions are well equipped to find this out before they take on employment. Furthermore, Global Consulting, for example, makes a point of describing the dread as well as the glamour in their recruitment process, admittedly in a way that gives working 80 hours a week a certain sex appeal. On the other hand, it seems wrong to 
only fault the seduced for falling for the seduction. It is clear that both Global Consulting and Elite Consulting work hard to hand down preferred perceptions and aspirations that very much revolve around the notion of creativity, innovation, elitism and empowerment. Employees are promised swift promotion, rich pecuniary and symbolic remuneration, and challenging and developing tasks. All of this fosters an ideational construction of the consulting identity. Indeed, it is here that, we claim, the key lies to the puzzle of reported boredom in knowledge work.

\section{Identity Regulation: The Bored Self as an Arrested Identity}

Our data shows how in these knowledge work environments, like Global Consulting and Elite Consulting, identity regulation importantly shapes the employees' constructions of themselves in relation to work and organization. In particular, management discourse provides distinctive discursive material to construct what it means to be a consultant. Thus, implicitly or explicitly the expert, autonomy, creativity, learning and elite discourses foster and regulate a certain version of selfhood. As the data also demonstrates, such a version of self is deemed as being attractive; it is one consultants aspire to - something that can explain the potency of identity regulation in this context (Alvesson \& Kärreman, 2007a, Thornborrow \& Brown, 2009, Costas \& Kärreman, 2013; Costas \& Grey, 2013). The management discourses are saturated with meanings that aim to persuade employees that they are the vanguard of the knowledge economy. This idealized conception of the knowledge worker is also reinforced externally, i.e. such as the images provided by the business press and popular management discourse (Prichard et al., 2000; Thrift, 2005; Doogan, 2009).

This explains why individuals entering these kinds of firms have such high expectations in terms of glamour, excitement and so forth and, indeed, construct their identities around these notions. It is these expectations that are perceived as being unmet when entering the firms. They entail excessive aspirations concerning not only the nature of 
knowledge work but also of being able to enact such an idealized version of self that are not fulfilled in everyday work experience: doing boring work turns into being bored. That is, the work activities can involve repetitive, unchallenging and unglamorous tasks, which clash with the understanding, image and hence the meaning of the consultant identity. The reports of boredom, we suggest, result from "misaligned expectations" (Conrad, 1997). Conrad argues that the construction of boredom depends on individuals' expectations with respect to a certain situation:

One of the fundamental attributes of boredom may be misaligned expectations. It is possible that we would not be bored if we did not expect more from situations. In our society we expect stimulation and connections from certain situations and events and may feel bored when social occasions fall short of our expectation (1997: 474).

Of course not every misaligned expectation leads to boredom. However, our data suggest that this plays a significant role here; the workings of identity regulation foster expectations of a particular consultant identity yet consultants experience this very identity as impossible to enact. This, we propose, leads to a particular state of the self: the bored self.

In this sense, knowledge work arrangements that particularly engage in excessive forms of identity regulation can be argued to be, somewhat paradoxically, susceptible for producing the bored self. Moreover, in companies, like Elite and Global Consulting, boredom constitutes a taboo, as it undermines the ideational consulting identity. This implies that consultants are not prepared for such experiences of boredom - something that may in fact reinforce them.

But why do consultants describe this state of the self as bored (instead of, say, simply frustrated and disappointed)? One way to explain this relates to the ways in it allows them to keep up their sense of a superior self, i.e. that they are in fact over-qualified, under-challenged 
and under-stimulated in their consulting work life. Put differently, they cling on to a selfunderstanding that informs themselves that they are better and deserve better than this. This points to an interesting identity dynamic that we suggest is different from extant understandings of employee interaction with identity regulation (e.g. Holmer-Nadesan, 1996; Pratt, 2000; Elsbach \& Battacharya, 2001; Fleming \& Spicer, 2003; Kunda, 2006; Costas \& Fleming, 2009). Identification assumes that the consultants feel able to fully enact the desired consulting self (which some indeed did but not the bored selves we focus on in this paper). In the context of Global Consulting and Elite Consulting identification means that consultants become "the useful enthusiast," as one informant put it above, who believes they can live out the identity constructions based on the discourses of creativity, autonomy, learning, expertise and elite in their work life.

Dis-identification, on the other hand, would imply that individuals distance themselves from the consulting identity suggested by management discourse wholesale by constructing their self around alternative discourses, e.g. 'I am actually an engineer and not a consultant'. Self-alienation means that they struggle to even produce such an alternative self. Ambivalence would occur when they construct themselves around certain aspects of the suggested consulting identity, whilst distancing themselves from other (e.g. 'I am an expert but do not want to be seen as elitist').

The bored self differs from these identity interactions with identity regulation: there is an identification with the identity fostered by management discourse, yet this clashes with the experiences of everyday work that does not allow for its enactment. In other words, the bored self is neither simply an example of ambivalence, dis-identification or self-alienation, nor one of identification. As our data show, the consultants struggle with and in fact experience themselves in ways that contradict the idealized version of the consulting identity to which they, however, still hold on to. Their distancing from the consulting identity arises from their sense of impossibility of enacting it. The bored self appears to be attached to the half-way 
house between identification and dis-identification. What makes this significant is the ways in which it produces what we term an arrested identity.

An arrested identity is one where individuals are drained from drives to mobilize alternative selves and thus engage in resistance. This might add explanation to the lack of resistance noted in such work arrangements (Kärreman \& Alvesson, 2009; Thornborrow \& Brown, 2009; Costas \& Grey, 2013). The bored self arrests their identity as it implies that they still subscribe to the consulting dream, while enduring the disappointment of the work experience blaming the stupid work, and not themselves and their aspirations. One consequence of the bored self is the ways in which it displaces agency from the individual to the company; that is their identity work is arrested both by them buying into the aspirations articulated by company discourse, yet feeling unable to fulfill them.

Moreover, the bored self arrests their identity by the ways in which it involves the sense of stagnating rather than developing, as we empirically analyzed above. In this sense, the reported bored self is corroborated by the ways in which boredom is often linked to time, namely the experience of the present as never-ending and therefore stagnating, as Heidegger famously developed in his example of waiting for the train (Svendson, 2005). What we have here is the sense of stagnation and aimlessness rather than of change and purpose (see also Darden \& Marks, 1995; Johnson, 2011). The resulting arrested identity therefore undermines possibilities of developing and mobilizing alternative selves, at least for the moment in which the actors construct themselves as bored.

\section{Excesses of Identity Regulation in Knowledge Work}

One might wonder why such organizations as Elite Consulting and Global Consulting take the risks in painting a too pretty picture of the nature of their work and the consulting identity. After all, these companies are not McDonald's, and their work practices are very distant from flipping burgers the Ronald McDonald way. Tradition is likely to play a role here. Not very 
long ago, management consultancy, law work and accountancy, for example, was much more like craft and much less like assembly work, and not the business of the freshly graduated. In this sense, the image of consultancy work may have evolved less quickly than actual practice, thus inadvertedly setting up a structural mis-alignment of expectations.

A more speculative take is to highlight the functions of boredom. Whether by design or by default, the set-up described here functionally operates as an elaborate selection mechanism, geared towards weeding out the rash and the impatient, and rewarding those taking the long view. The glamour attracts a relatively large pool of talented and energetic graduates, while boring work eliminates those who lack stamina and team player capabilities. This might explain the high personnel turnover at these firms, and perhaps makes it more of a solution than a problem - at least for the companies.

It is also important to point out that, although boring, the work often produces tangible outputs. Among other things, this makes it easier for the company to persuade clients that they have got value for money, which is very often a maddening issue in knowledge work given the inherent ambiguity of what knowledge is (Alvesson, 1993). In this sense, the outcomes of boring work may be used as a tool for impression management (Clark 1995), deployed to convince clients that serious efforts have indeed been involved, as demonstrated by reports, presentations, programs, databases and so on.

Having said that, there are some obvious issues. For example, boredom does not seem to be a very precise selection mechanism. There is no indication in our empirical material that junior organizational members anticipate the test character of boredom and use it as information in their career planning. The companies do not leave any clear hints of this either, officially or unofficially. Thus, it is possible that people who leave are not necessarily the right ones, from the company's point of view. The unfilled aspirations produced by company discourse can have further costs. They may breed disbelieve in company discourse, and in the 
long run systemically distort company communication, resulting in issues around trust and loyalty.

\section{Conclusion}

In this article we have discussed reported experiences of boredom in knowledge work. Rather than finding the work as creative, innovative and complex, individuals describe it as boring something that contradicts the image of knowledge work. Of course, this is not to say that boredom is necessarily an inherent feature of knowledge work. As we pointed out before, not every individual at the consultancy firms expressed such an experience. Moreover, one might also argue that the kind of work environment we investigated is particular: the knowledgeintensive firms are large and thus have bureaucratic processes in place, e.g. in relation to HRM systems, hierarchy; the kind of consultancy work these firms offer entails the use of standardized methodologies and implementations. Having said that, the companies are similar to other knowledge work environments in that they employ highly qualified individuals and stress creativity, innovation, autonomy, learning and development in relation to work. Thus, the reported experiences of boredom constitute a surprising phenomenon. Furthermore, we could also imagine that such experiences could arise in work contexts (e.g. in the arts and research) with similar dynamics, i.e. high aspirations, discourses of freedom and selfactualization.

We propose that such boredom is an outcome of the identity regulation fostered by the company discourses around expertise, creativity, learning, autonomy and elite. These discourses construct a distinctive, namely attractive and seductive, consulting identity that individuals, on the one hand, aspire to but, on the other hand, struggle to enact in everyday work experience. As a result, they develop a bored self. Interestingly, the construction of the 
self as bored in fact allows them to maintain their aspirations and idealized understandings of themselves. We suggest that this phenomenon can be understood as an arrested identity.

In drawing attention to the bored self as an arrested identity, we contribute to extant conceptualizations of employee interactions with identity regulation, such as identification, dis-identification and so on. The bored self makes it possible to both hang on to the aspirational aspects of the identity suggested by company discourse whilst dealing with its disappointments. It becomes arrested as the sense of stagnation prevails. This has important implications in that agency is displaced away from individuals, which drains efforts towards mobilizing alternative selves. In this sense, the employee work experiences presented in this article shed light on the importance of people's everyday work practices in their understanding of selfhood - something that we believe studies of identity need to take more into account. Fancy images, fun cultures and glamorous offices, so often associated to knowledge work - all those things around which positive identities can be constructed cannot completely offset individuals' experiences of their day to day work, especially if they run contradictory to the celebrated organizational identity.

\section{References}

Alvesson, M. (1993) 'Organizations as Rhetoric: Knowledge-Intensive Firms and the Struggle with Ambiguity.' Journal of Management Studies, 30 (6), pp. 997-1015.

Alvesson, M. (2004) Knowledge Work and Knowledge-Intensive Firms. Oxford: Oxford University Press. 
Alvesson, M., Ashcraft, K. L. \& Thomas, R. (2008) 'Identity Matters: Reflections on the Constructions of Identity Scholarship in Organization Studies.' Organization, 15 (1), pp. 5-28.

Alvesson, M., \& Kärreman, D. (2004). Interfaces of control. Technocratic and socioideological control in a global management consultancy firm. Accounting, Organizations and Society, 29(3), 423-444.

Alvesson, M \& D. Kärreman. (2007a) Unraveling HRM: identity, ceremony, and control in a Management Consultancy Firm. Organization Science 18, pp. 711-723

Alvesson, M. \& Kärreman. D. (2007b) 'Constructing Mystery: Empirical Matters in Theory Development.' Academy of Management Review, 32 (4), pp. 1265-1281.

Alvesson, M., \& Kärreman, D. (2011). Qualitative research and theory development: Mystery as method. Sage Publications.

Alvesson, M. \& Willmott, H. (2002) 'Identity Regulation as Organizational Control: Producing the Appropriate Individual.' Journal of Management Studies, 39 (5), pp. 619-644.

Anderson-Gough, F., Grey, C. \& Robson, K. (2000) 'In the Name of the Client: The Service Ethic in Two Professional Services Firms.' Human Relations, 53 (9), pp. 1151-1174.

Anderson-Gough, F., Grey, C. \& Robson, K. (2001) 'Test of Time: Organizational TimeReckoning and the Making of Accountants in Two Multi-National Accounting Firms.' Accounting, Organizations and Society, 26 (2), pp. 99-102. 
Barley, S. R. \& Kunda, G. (1992) 'Design and Devotion: Surges of Rational and Normative Ideologies of Control in Managerial Discourses.' Administrative Science Quarterly, 37 (3), pp. 363-399.

Barley, S. \& Kunda, G. (2001) ‘Bringing Work Back In’, Organization Science, 12, pp. 76-95.

Blackler, F. (1995). 'Knowledge, knowledge work and organizations: An overview and interpretation'. Organization Studies, 16(6), 1021-1046.

Brown, A. \& Lewis, M. (2011) Identities, Disipline and Routines. Organization Studies, 32 (7), pp. 871-895.

Burawoy, M (1979) Manufacturing Consent: Changes in the Labor Process under Monopoly Capitalism. Chicago, IL: The University of Chicago Press.

Carroll, B., \& Nicholson, H. (2014). Resistance and struggle in leadership development. $\mathrm{Hu}$ man Relations, 0018726714521644.

Carroll, B. J., Parker, P. \& Inkson, K. (2010) 'Evasion of Boredom: An Unexpected Spur to Leadership.’ Human Relations, 63 (7), pp. 1031-1049.

Casey, C. (1995) Work, Self and Society. London: Routledge.

Clark, T. (1995) Managing Consultants: Consultancy as the Management of Impression. Buckingham: Open University Press. 
Collinson, D. L. (1992) Managing the Shopfloor: Subjectivity, Masculinity and Workplace Culture. Berlin: De Gruyter.

Collinson, D. L. (2003) 'Identities and Insecurities: Selves at Work.' Organization, 10 (3), pp. $527-547$

Conrad, P. (1997) 'It's Boring: Notes on the Meaning of Boredom in Everyday Life.' Qualitative Sociology, 20 (4), pp. 465-475.

Cornelissen, J. P. (2006). Metaphor and the Dynamics of Knowledge in Organization Theory: A Case Study of the Organizational Identity Metaphor*. Journal of Management Studies, 43(4), 683-709

Costas, J. (2012) "We Are All Friends Here" - Reinforcing Paradoxes of Normative Control in a Culture of Friendship. Journal of Management Inquiry, 21 (4), 377-395.

Costas, J. \& Fleming, P. (2009) 'Beyond Dis-identification: A Discursive Approach to Selfalienation in Contemporary Organizations.' Human Relations, 62 (3), pp. 353-378.

Costas, J. \& Grey, C. (2013) 'The Power of Temporality and the Temporality of Power: Imaginary Future Selves in Professional Service Firms'. Organization Studies. 35 (6), pp. 909937.

Costas, J \& Kärreman, D. (2013) Conscience as Control: Managing Employees through CSR. Organization, 20 (3), pp. 394-415. 
Covaleski, M.A., Dirsmith, M.W., Heian, J.B. \& Samuel, S. (1998) 'The calculated and the avowed: Techniques of discipline and struggles over identity in Big Six public accounting firms.' Administrative Science Quarterly, 43, pp. 293-327.

Darden, D. \& Marks, A (1999) 'Boredom: A socially disvalued emotion.' Sociological Spectrum, 19 (1), pp. 13-37.

Doogan, K. (2009) New Capitalism? The Transformation of Work. Malden: Polity Press.

Elsbach, K. (1999) ‘An Expanded Model of Organizational Identification.’ Research in Organizational Behaviour, 21 (1), pp. 163-200.

Elsbach, K.D. \& Bhattacharya, C.B. (2001) 'Defining Who You Are By What You're Not: Organizational Disidentification and the National Rifle Association.' Organization Science, 12 (4), pp. 393-413.

Empson, L. (2004). Organizational identity change: managerial regulation and member identification in an accounting firm acquisition. Accounting, Organizations and Society, 29(8), 759781

Fisher, C. D. (1993) 'Boredom at Work: A Neglected Concept:' Human Relations, 46 (3), pp. 395-417.

Fleming, P. \& Spicer, A. (2003) 'Working at a Cynical Distance: Implications for Power, Subjectivity and Resistance.' Organization, 10 (1), pp. 157-179. 
Fleming, P., \& Sturdy, A. (2009). “Just be yourself!”: Towards neo-normative control in organisations?. Employee Relations, 31(6), 569-583.

Genmill, G. \& Oakley, J. (1992) 'The Meaning of Boredom in Organizational Life.' Group \& Organization Management, 17 (4), pp. 358-369.

Gioia, D., Schultz, M., K. Corley (2000) Organizational Identity, Image, and Adaptive Stability. Academy of Management Review, 25(1) 63-81.

Goodstein, E. S. (2005). Experience without qualities: boredom and modernity. Stanford University Press.

Grey, C. (1994) 'Career as a Project of the Self and Labour Process Discipline.' Sociology, 28 (2), pp. 479-497.

Healy, S. D. (1984). Boredom, self, and culture. Rutherford, NJ: Fairleigh Dickinson University Press.

Holmer-Nadesan, N. (1996) 'Organizational Identity and Space of Action.' Organization Studies, 17 (1), pp. 49-81.

Johnsen, R. (2011) On Boredom: A Note on Experience Without Qualities. Ephemera, 11 (4), pp. 482-489.

Kafry, D. \& Pines, A. (1980) 'The Experience of Tedium in Life and Work.' Human Relations, 33 (7), pp. 477-503. 
Kärreman. D. (2010) 'The Power of Knowledge: Learning from 'Learning by KnowledgeIntensive Firm'. Journal of Management Studies, 47 (7), pp. 1405-1416.

Kärreman, D. \& Alvesson, M. (2004) 'Cages in Tandem, Management Control Social Identity, and Identification in a Knowledge-Intensive Firm.' Organization, 11 (1), pp. 149175.

Kärreman, D., \& Alvesson, M. (2009). Resisting resistance: Counter-resistance, consent and compliance in a consultancy firm. Human Relations, 62(8), 1115-1144.

Kondo, D. K. (1990) Crafting Selves: Power, Gender, and Discourses of Identity in a Japanese Workplace. Chicago, IL: University of Chicago Press.

Kosmala, K. \& Herrbach, O. (2006) 'The Ambivalence of Professional Identity: On Cynicism and Jouissance in Audit Firms.' Human Relations, 59 (10), pp. 1393-1428.

Kuhn, T. A. (2006) “'Demented Work Ethic' and a 'Lifestyle Firm': Discourse, Identity, and Workplace Time Commitments.' Organization Studies, 27 (9), pp. 1339-1358.

Kunda, G. (2006) Engineering Culture, $2^{\text {nd }}$ ed. Philadelphia, PA: Temple University Press.

Land, C. \& Taylor. S. (2010) 'Surf 's Up: Work, Life, Balance and Brand in a New Age Capitalist Organization.' Sociology, 44, pp. 395-413.

Locke, K., Golden-Biddle, K. \& Feldman, M. (2008) 'Making Doubt Generative: Rethinking 
the Role of Doubt in the Research Process.' Organization Science, 19 (6), pp. 907-918.

Lowendahl B. (1997) Strategic Management of Professional Service Firms. Copenhagen: Handelshojskolens Forlag.

Loukidou, L., Loan-Clarke, J. \& Daniels, K. (2009) 'Boredom in the workplace: More than monotonous tasks.' International Journal of Management Reviews, 11 (4), pp. 381-405.

Melamed, S., Benavi, I., Luz, J., \& Green, M. S. (1995) 'Objective and subjective work monotony: Effects on job-satisfaction, psychological distress, and absenteeism in blue-collar workers'. Journal of Applied Psychology, 80, pp. 29-42.

Morris, T. \& Empson, L. (1998) 'Organization and expertise: An exploration of knowledge bases and the management of accounting and consulting firms.' Accounting, Organizations and Society, 23, pp. 609-24.

Newell, S., Roberston, M., Scarbrough, H. \& Swan, J. (2009) Managing Knowledge and Innovation, 2nd ed. Basingstoke: Palgrave Macmillan.

Nicholson, H., \& Carroll, B. (2013). Identity undoing and power relations in leadership development. Human Relations, 66(9), 1225-1248.

Parker, M. (2000) Organizational Culture and Identity. London: Sage.

Poulter, D. \& Land, C. (2008) 'Preparing to work: dramaturgy, cynicism and normative 're- 
mote' control in the socialization of graduate recruits in management consulting.' Culture and Organization, 14 (1), pp. 65-78.

Pratt, M. (2000) 'The Good, the Bad and the Ambivalent: Managing Identification Among Amway Distributors.' Administrative Science Quarterly, 45 (3), pp. 456-493.

Prichard, C., Hull, R., Chumer, M. \& Willmott, H. (eds.) (2000) Managing Knowledge. Critical Investigations of Work and Learning. Basingstoke: MacMillan.

Roberts, J. (2005) 'The Power of the 'Imaginary' in Disciplinary Processes.' Organization, 12 (5), pp. 621-645.

Robertson, M. \& Alvesson, M. (2006) 'The Best and the Brightest: The Construction, Significance and Effects of Elite Identity in Consulting Firms.' Organization, 13 (2), pp. 195 224.

Roy, D. F. (1960) “"Banana Time”: Job Satisfaction and Informal Interaction.' Human Organization, 18 , pp. 158-68.

Taylor, P., \& Bain, P. (2003). 'Subterranean worksick blues': humour as subversion in two call centres. Organization Studies, 24(9), 1487-1509.

Thompson, P., Warhurst, C., \& Callaghan, G. (2001). Ignorant theory and knowledgeable workers: interrogating the connections between knowledge, skills and services. Journal of Management Studies, 38(7), 923-942. 
Sennett, R. (1998) The Corrosion of Character. London: W.W. Norton \& Company Ltd.

Spacks, P. M. (1995) Boredom: The Literary History of a State of Mind. Chicago, IL: University of Chicago Press.

Starbuck, W. H. (1992) 'Learning by Knowledge-Intensive Firms.' Journal of Management Studies, 29 (6): 713-740.

Sturdy, A. \& Wright, C. (2008) 'A Consulting Diaspora? Enterprising Selves as Agents of Enterprise.' Organization, 15 (3), p. 427-444.

Sveningsson, S. \& Alvesson, M. (2003) 'Managing Managerial Identities: Organizational Fragmentation, Discourse and Identity Struggle.' Human Relations, 56 (10), pp. 1163-1193.

Thomas, R. \& Davies, A. (2005) 'Theorizing the Micro-Politics of Resistance: New Public Management and Managerial Identities in the UK Public Services.' Organization Studies, 26 (5), pp. 683-706.

Thornborrow, T., A. D. Brown (2009) 'Being Regimented': Aspiration, Discipline and Identity Work in the British Parachute Regime. Organization Studies. 30(4) 355-376.

Thrift, N. (2005) Knowing Capitalism. London: Sage.

Van Maanen, J. (1979) The Fact of Fiction in Organizational Ethnography. Administrative Science Quarterly, 24, pp. 539-549. 
Van Maanen, J. (1991) 'The Smile Factory: Work at Disneyland.' In Frost, P., Moore, L., Lewis, M. Lumberg, C. \& Martin, J. (eds). Reframing Organizational Culture. Newbury Park, CA: Sage, pp. 58-76.

Van Maanen J., Sørensen J.B., Mitchell T.R. (2007) 'Introduction to special topic forum: the interplay between theory and method.' Academy of Management Review, 32 (4), pp. 1145-1154.

Van der Heijden, G. A. H., Schepers, J. J. L. \& Nijssen, E. J. (2011) 'Understanding workplace boredom among white collar employees: Temporary reactions and individual differences.' European Journal of Work and Organizational Psychology.

Vodanovich, S.J. (2003) Psychometric measures of boredom: a review of the literature. Journal of Psychology, 137, pp. 569-595.

Watson, T. J. (2008) 'Managing Identity: Identity Work, Personal Predicaments and Structural Circumstances.' Organization, 15 (1), pp. 121-143.

Willis, P. E. (1977). Learning to labor: How working class kids get working class jobs. Columbia University Press.

Ybema, S., Keenoy, T., Oswick, C., Beverungen, A., Ellis, N. \& Sabelis, I. (2009) 'Articulating Identities.' Human Relations, 62 (3), pp. 299-322. 
